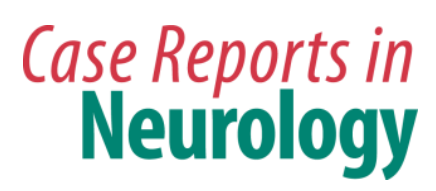

\title{
Trigeminal Neuralgia as the First Clinical Manifestation of Anti-Hu Paraneoplastic Syndrome Induced by a Borderline Ovarian Mucinous Tumor
}

\author{
Hossein Kalanie Ali Amini Harandi Masoud Mardani Zohre Shahverdi \\ Arman Morakabati Shapoor Alidaei Daryoosh Heydari \\ Ziaeddin Soroush Hossein Pakdaman Zahra Hosseinzadeh
}

Neurology Research Center, Mehr General Hospital, Tehran, Iran

\section{Key Words}

Trigeminal neuralgia $\cdot$ Paraneoplastic syndrome $\cdot$ Anti-Hu $\cdot$ Ovarian tumor

\begin{abstract}
Paraneoplastic neurologic syndrome (PNS) is an uncommon manifestation of cancer that is not caused by the tumor or metastasis. Trigeminal neuralgia (TN) is an initial symptom of this disease, but it has rarely been reported in the literature. Here, we report the case of a 76year-old woman who presented with classic TN, followed by limbic encephalitis due to an underlying ovarian intestinal-type mucinous borderline tumor, with the presence of anti-Hu antibodies. She recovered quickly after removal of the tumor and was essentially free of symptoms 2 weeks after surgery. Because PNS precedes the tumor in approximately $60 \%$ of cases, its rapid detection and treatment are crucial. Therefore, we propose that PNS be considered during the management of TN when brain imaging is normal, as it is followed by other central and/or peripheral neurological manifestations as well as the presence of systemic symptoms such as anemia, fatigability, loss of appetite, or weight loss.
\end{abstract}


Kalanie et al.: Trigeminal Neuralgia as the First Clinical Manifestation of Anti-Hu Paraneoplastic Syndrome Induced by a Borderline Ovarian Mucinous Tumor

\section{Introduction}

Trigeminal neuralgia (TN) is a sudden, unilateral, brief, stabbing, recurrent pain, localized to one or more divisions of the fifth cranial nerve. It is classified into primary (idiopathic or classic) and secondary or symptomatic TN [1]. The precise etiology of primary TN is unknown, although vascular compression is often accepted as the origin of pain [2]. However, symptomatic TN is thought to have a manifested cause such as tumors, infarct, or multiple sclerosis. Thus, management of TN essentially depends upon its etiology.

Although most TN cases have long been called idiopathic [1], neuropathy of the trigeminal nerve (fifth cranial nerve) can involve its full course, from its nuclei in the brain stem to its peripheral branches. Therefore, imaging is needed to visualize the entire course of the trigeminal nerve to exclude the possibility of a structural lesion. If the imaging results are normal, laboratory tests should be considered to exclude neuralgia caused by infectious agents or connective tissue diseases and vasculitis. Although paraneoplastic neurologic syndrome (PNS) is infrequent [3], rare cases of facial sensory neuropathy have been diagnosed as PNS $[4,5]$. Here, we report a case of classic TN with positive onconeural antibodies (anti-Hu), followed by limbic encephalitis (LE), which called for rapid detection and removal of an ovarian intestinal-type mucinous borderline tumor, resulting in the rapid recovery of the patient.

\section{Case Report}

On June 5, 2012, a 76-year-old female patient was transported to the Intensive Care Unit of Mehr General Hospital (Tehran, Iran) via ambulance. She had a 3-week history of progressive somnolence, confusion, agitation, symptoms of depersonalization, and visual hallucinations. Her disorder began 12 weeks prior to her current admission, with daily and repeated short, sharp, lancinating, electric shock-like pain involving the left lower division of the fifth cranial nerve. She was taken to a local hospital in another city, where she underwent neurological evaluation by magnetic resonance imaging (MRI) and electroencephalography (EEG), with normal results. The patient was instructed to take $200 \mathrm{mg}$ carbamazepine 3 times a day, which partially relieved her pain episodes. Eight weeks later, and following attacks of nocturnal hallucinations, a neurologist prescribed $5 \mathrm{mg}$ olanzapine to be taken each night. However, her mental and psychiatric state deteriorated, and she was transferred to Mehr General Hospital.

On physical examination, the patient was afebrile. Scars from a coronary artery bypass surgery performed in 2008 were present on her anterior chest wall. Her lungs were clear, and no lymphadenopathy or organomegaly was detected. Neurological evaluation revealed an awake, agitated, confused woman with garbled and incoherent speech. She was easily distracted by irrelevant stimuli and could not sustain attention. No carotid bruit or stiff neck was detected. Cranial nerves were grossly normal, and no sensory or motor abnormalities were detected in the fifth cranial nerve. Corneal, orbicularis oculi, and sneeze reflexes were intact. Her motor power was $5 / 5$ in all 4 extremities, her deep tendon reflexes were $2 / 4$ in the arms and 1/4 in the legs, she had normal flexor plantar responses, and no abnormalities were seen in gait or coordination.

Brain MRI, MR angiography, and MR venography were normal. EEG showed moderately diffuse slowing (fig. 1). A lumbar puncture was performed, and the results of the cerebrospinal fluid analysis are shown in table 1 . To avoid any possible treatable diagnosis, intravenous 
phenytoin and acyclovir were started, but acyclovir was stopped 5 days later when the final diagnosis was achieved. Quetiapine was administered to keep the patient calm.

Blood tests showed an elevated erythrocyte sedimentation rate $(40 \mathrm{~mm}$ after $1 \mathrm{~h}$; normal: $<20 \mathrm{~mm})$ with normal complete blood count, and low hemoglobin $(10.6 \mathrm{mg} / \mathrm{dl}$; normal: 12-16 mg/dl). Liver and kidney function tests and blood sugar levels were normal. Immunologic tests showed negative anti-Ro, anti-nuclear, and anti-neutrophil cytoplasmic antibodies. Serum protein electrophoresis and angiotensin-converting enzyme levels were normal. Broad serological screening assays for infectious conditions, including HIV, herpes simplex virus 1 and 2, hepatitis, Lyme disease, syphilis, and tuberculosis using the intermediate-strength purified protein derivative skin test, were negative. Tumor markers, including carbohydrate antigen (CA)-125, CA-19.9, CA-15.3, CA-242, carcinoembryonic antigen, serum alpha-fetoprotein, and anti-Ri and anti-Yo antibodies were not detected, but anti-Hu antibodies were present in the serum, as visualized by dot blot and indirect immunofluorescence techniques.

To localize the suspected malignancy, the patient underwent computed tomography scans of the chest and abdomen, which disclosed a large mass in the left ovary (fig. 2). She underwent surgery, and a 20 -cm ovarian intestinal-type mucinous tumor (fig. 3) was removed. After surgery, the patient recovered quickly. After 2 weeks, she was alert and oriented with normal speech. Her second EEG at this stage was normal (fig. 4). Two months after the operation, the patient was pain-free, and her carbamazepine and phenytoin were gradually discontinued. At her last follow-up visit in March 2013, the patient was well and free of symptoms.

\section{Discussion}

PNS is a rare, cancer-associated disorder [3] that is detected before cancer diagnosis in $80 \%$ of cases [6]. PNS results from immune cross-reactivity between tumor cells and components of the nervous system [7]. In response to the developing tumor, a patient produces tumor-directed antibodies known as onconeural antibodies (ONAs). Due to antigenic similarity, these ONAs and associated ONA antigen-specific T lymphocytes [8] inadvertently attack components of the nervous system. Here, we present a case of classic $\mathrm{TN}$, followed by LE due to an underlying ovarian intestinal-type mucinous borderline tumor.

Cranial nerve involvement including TN is one manifestation of anti-Hu-associated brainstem encephalitis [9], which is associated with small-cell lung carcinoma in most patients. The frequency of trigeminal involvement in patients with anti-Hu antibodies is unknown. In a report by Dalmau et al. [10], facial numbness was described in 2 of 23 patients with brainstem encephalitis, and Demarquay et al. [4] reported signs of fifth cranial nerve neuropathy as the first manifestation of anti-Hu-positive PNS. Although TN is a wellknown symptom in patients with anti-Hu-associated PNS, there are few reports of TN in the literature in this regard. In fact, of the 33 cases of facial pain as the first manifestation of lung cancer reported in the literature in 2003 [11], only 2 patients had a previous diagnosis of TN. In our study, LE appeared after TN, with a subacute onset of short-term memory loss, confusion, and psychiatric symptoms, in addition to elevated cells and protein in the patient's cerebrospinal fluid and positive oligoclonal bands in the serum.

LE is a neurological condition associated with various tumors, such as small-cell lung cancer, testicular germ cell neoplasms, breast cancer, and 3-4\% of ovarian teratomas, which are usually associated with anti-N-methyl-D-aspartate receptor antibodies [12]. Anti-Hu antibodies are uncommonly reported in association with gynecological cancer (2.5\%) [13], 
and LE has not been reported in association with ovarian mucinous borderline tumors. Ten percent of ovarian epithelial tumors consist of mucinous tumors. A vast majority (75\%) of these tumors are benign, $10 \%$ are borderline, and $15 \%$ are invasive carcinomas [14]. Histologically, ovarian intestinal-type mucinous borderline tumors are composed of multiple cysts and glands of various sizes that are lined with a mixture of cell types, including endocervical, gastric, and neuroendocrine cells [15]. These neuroendocrine cells may have been the source of ONA secretion in the serum of our patient.

To the best of our knowledge, this study is the first reported case of PNS produced by an ovarian intestinal-type mucinous borderline tumor with anti-Hu antibodies and clinical presentation of idiopathic TN followed by LE. We propose that PNS be considered during the management of TN when brain imaging is normal, as it is followed by other central and/or peripheral neurological manifestations and the presence of systemic symptoms, such as anemia, fatigability, loss of appetite, or weight loss.

\section{References}

1 Truini A, Galeotti F, Cruccu G: New insight into trigeminal neuralgia. J Headache Pain 2005;6:237-239.

-2 Barker FG 2nd, Jannetta PJ, Bissonette DJ, Larkins MV, Jho HD: The long-term outcome of microvascular decompression for trigeminal neuralgia. N Engl J Med 1996;334:1077-1083.

-3 Kannoth S: Paraneoplastic neurologic syndrome: a practical approach. Ann Indian Acad Neurol 2012;15:612.

4 Demarquay G, Didelot A, Rogemond V, Ryvlin P, Gouttard M, Garassus P, Mauguière F, Honnorat J: Facial pain as first manifestation of anti-Hu paraneoplastic syndrome. J Headache Pain 2010;11:355-357.

5 Cerase A, Brindisi L, Lazzeretti L, Pepponi E, Venturi C: Lung cancer presenting with trigeminal neuropathy. Neurol Sci 2011;32:927-931.

6 Honnorat J, Antoine JC: Paraneoplastic neurological syndromes. Orphanet J Rare Dis 2007;2:22.

7 de Beukelaar JW, Sillevis Smitt PA: Managing paraneoplastic neurological disorders. Oncologist 2006;11:292-305.

-8 Albert ML, Austin LM, Darnell RB: Detection and treatment of activated T cells in the cerebrospinal fluid of patients with paraneoplastic cerebellar degeneration. Ann Neurol 2000;47:9-17.

-9 Saiz A, Bruna J, Stourac P, Vigliani MC, Giometto B, Grisold W, Honnorat J, Psimaras D, Voltz R, Graus F: AntiHu-associated brainstem encephalitis. J Neurol Neurosurg Psychiatry 2009;80:404-407.

10 Dalmau J, Graus F, Rosenblum MK, Posner JB: Anti-Hu-associated paraneoplastic encephalomyelitis/sensory neuronopathy. A clinical study of 71 patients. Medicine (Baltimore) 1992;71:59-72.

11 Sarlani E, Schwartz AH, Greenspan JD, Grace EG: Facial pain as first manifestation of lung cancer: a case of lung cancer-related cluster headache and a review of the literature. J Orofac Pain 2003;17:262-267.

-12 Dalmau J, Gleichman AJ, Hughes EG, Rossi JE, Peng X, Lai M, Dessain SK, Ros enfeld MR, Balice-Gordon R, Lynch DR: Anti-NMDA-receptor encephalitis: case series and analysis of the effects of antibodies. Lancet Neurol 2008;7:1091-1098.

-13 Honnorat J, Cartalat-Carel S, Ricard D, Camdessanche JP, Carpentier AF, Rogemond V, Chapuis F, Aguera M, Decullier E, Duchemin AM, Graus F, Antoine JC: Onco-neural antibodies and tumour type determine survival and neurological symptoms in paraneoplastic neurological syndromes with Hu or CV2/CRMP5 antibodies. J Neurol Neurosurg Psychiatry 2009;80:412-416.

14 Cosyns S, Leyder M, Bourgain C, De Sutter P: Invasive recurrence of an intestinal-type mucinous epithelial neoplasm of low malignant potential: case report and review of the literature. Case Rep Oncol 2011;4:426432.

15 Hart WR: Borderline epithelial tumors of the ovary. Mod Pathol 2005;18(suppl 2):S33-S50. 
Table 1. Analysis of cerebrospinal fluid

\begin{tabular}{lll}
\hline Variable & Results & $\begin{array}{l}\text { Reference } \\
\text { range adults }\end{array}$ \\
\hline $\begin{array}{l}\text { Opening pressure, cm H}{ }_{2} \mathrm{O} \\
\text { Color }\end{array}$ & $\begin{array}{l}40 \text { with leg flexed } \\
\text { colorless } \\
\text { clear }\end{array}$ \\
$\begin{array}{l}\text { Turbidity } \\
\text { Red blood cells, } / \mathrm{mm}^{3}\end{array}$ & 3 & \\
White blood cells, $/ \mathrm{mm}^{3}$ & 55 & \\
$\begin{array}{l}\text { Differential counts, \% } \\
\quad \text { Neutrophils }\end{array}$ & & \\
$\quad$ Lymphocytes & 0 & 0 \\
$\quad$ Monocytes & 96 & 0 \\
Glucose, mg/dl & 4 & 0 \\
Protein, mg/dl & 55 & $40-75$ \\
Oligoclonal bands & 70 & $15-45$ \\
Gram's stain & positive \\
Acid-fast smear & no organisms seen & \\
Culture & no organisms seen & \\
$\quad$ Routine & & \\
$\quad$ Fungal & sterile & \\
$\quad$ Mycobacterial & sterile & \\
Viral PCR & sterile & \\
Malignant cells & negative & \\
\hline
\end{tabular}

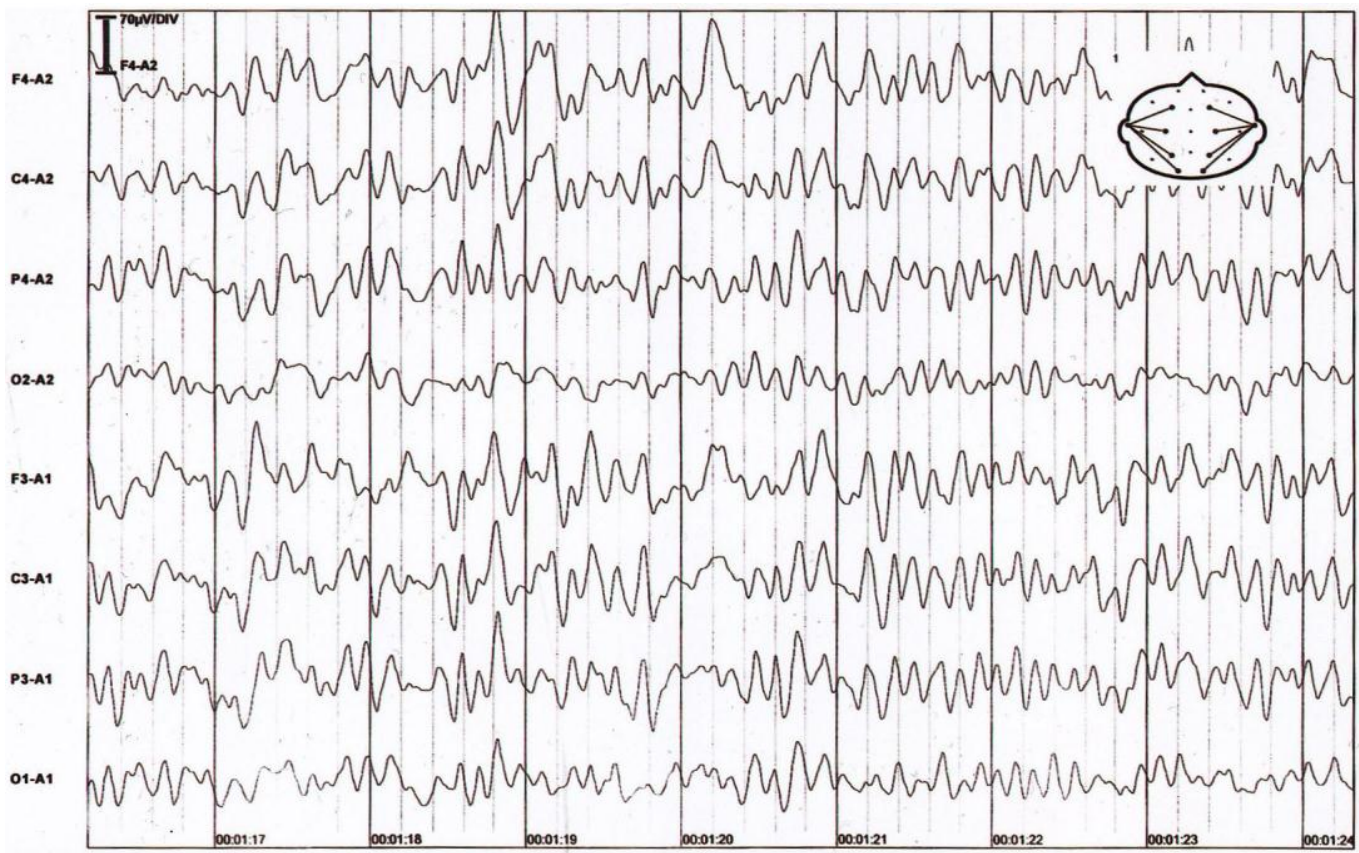

Fig. 1. Diffuse 2-3-Hz waves can be seen, remixed with sharp waves in the left frontal-central regions, superimposed on a fairly well-organized 5-6-Hz background rhythm. 




Fig. 2. Computed tomography of the pelvis shows a large, unevenly enhanced, heterogeneous solid-cystic tumor, with a thick septum on the left side. Solid and cystic parts of the tumor can be seen in circles 1 and 2 , respectively.

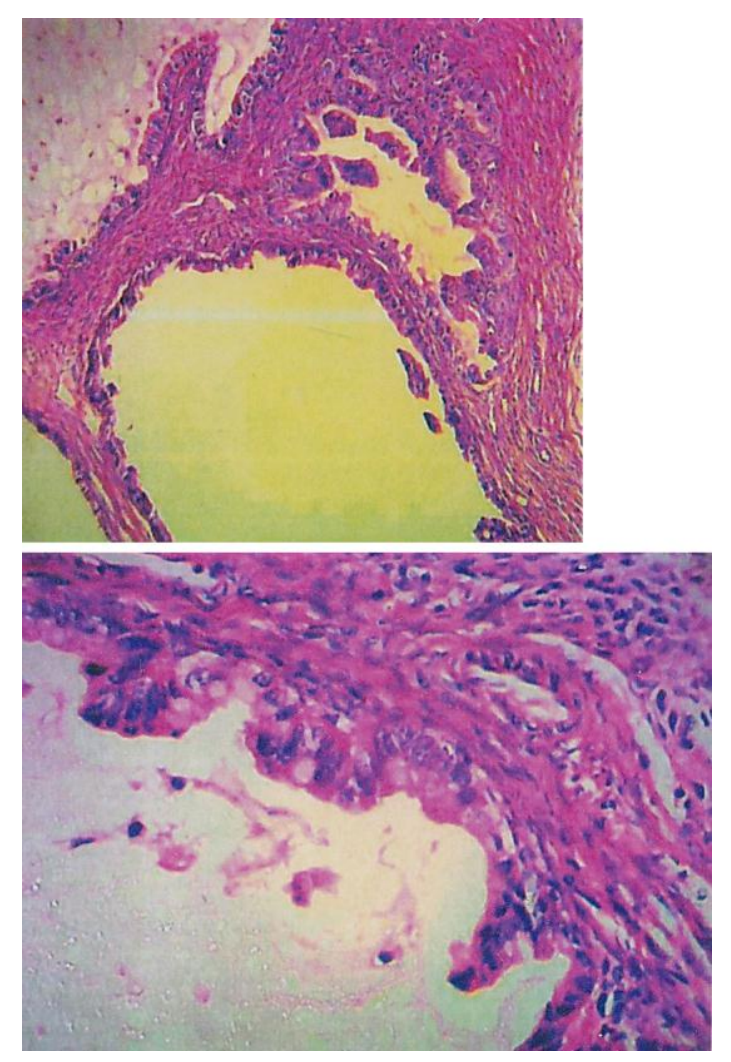

Fig. 3. H\&E-stained slides show glands and cysts of variable sizes with papillary tufting lined by gastrointestinal-type mucinous epithelium with mild to moderate atypia, a few goblet cells, and rare paneth cells. 
Kalanie et al.: Trigeminal Neuralgia as the First Clinical Manifestation of Anti-Hu

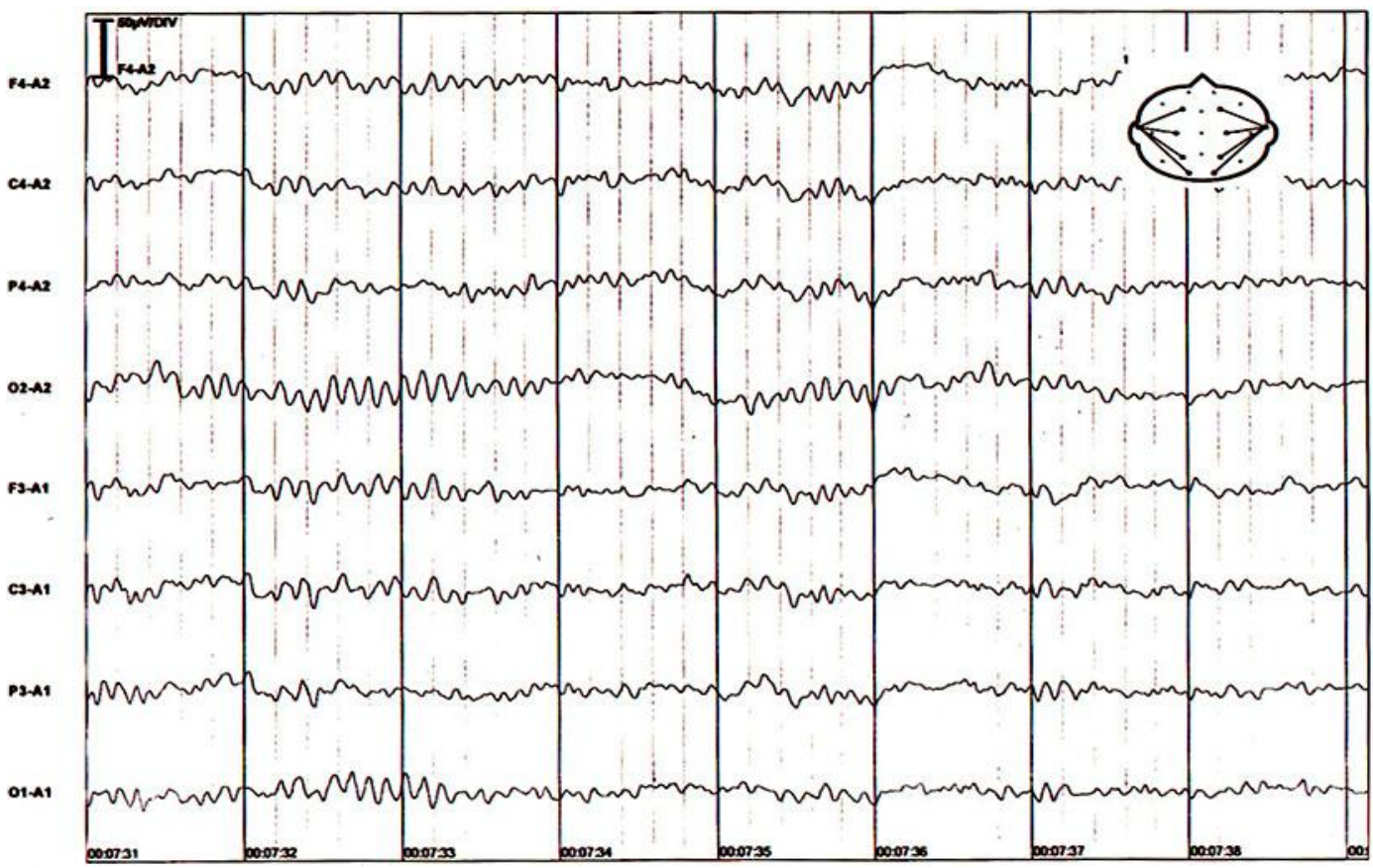

Fig. 4. A second EEG was done 2 weeks after surgery and was normal. It showed well-organized, bilaterally synchronous activity, and a symmetrical 7-9-Hz background rhythm, devoid of any slow or sharp waves. 